\title{
Crescimento e bromatologia do feijão-bravo (Capparis flexuosa L.) em área de Caatinga no Curimataú paraibano, Brasil ${ }^{1}$
}

\author{
Growth and bromatology of Capparis flexuosa at Curimatau region, Paraiba state, \\ Brazil
}

\author{
Jorge Xavier de Almeida Neto ${ }^{2 *}$, Albericio Pereira de Andrade ${ }^{3}$, Alecksandra Vieira de Lacerda ${ }^{4}$, Leonardo \\ Pessoa Félix ${ }^{5}$ e Divan Soares da Silva ${ }^{5}$
}

\begin{abstract}
Resumo - Este trabalho teve como objetivo caracterizar aspectos relacionados com o crescimento e a bromatologia do feijãobravo (Capparis flexuosa L.) em uma área no Curimataú, Semiárido Paraibano. Para a análise da evolução do crescimento desta espécie formou-se quatro grupos de plantas segundo a classe de altura: GI até 0,50 m; GII de 0,51 a $1 \mathrm{~m}$; GIII de 1,01 a 1,50 m e GIV a $\geq 1,51 \mathrm{~m}$. No período de março a dezembro de 2007 determinou-se a altura e o número de ramos dos indivíduos, sendo o diâmetro do caule registrado de março a setembro. Avaliou-se também, a composição bromatológica das folhas e talos do feijãobravo. Em todos os grupos, o feijão-bravo apresentou crescimento lento no período chuvoso. Entretanto, até o mês de agosto, observou-se o aumento no número de ramos das plantas, independente do grupo estabelecido. No Período amostrado, não se constatou diferença $(p>0,05)$ entre plantas em termos de diâmetro, em todos os grupos amostrados. Os dados bromatológicos registrados foram os seguintes: matéria orgânica (91,95\%); cinzas (8,05\%); matéria seca (47,1\%) e umidade (52,9\%). Os teores de proteína bruta (8,13\%); fibra bruta (32,32\%); extrato etéreo (5,37\%); e energia bruta (5.015 cal g-1) do feijão-bravo, dado a estas características, sugerem que esta espécie apresenta potencial para ser utilizada como forrageira.
\end{abstract}

Palavras-chave - Forrageira. Capparaceae. Semiárido. Região Nordeste. Valores Nutricionais.

\begin{abstract}
The general aim of this study was to describe the growth and bromatology of Capparis flexuosa L. in an area of Caatinga, Paraiba State, Brazil. To analyze the growth evolution, the plants were divided in four groups according to the height classes: GI until $0.50 \mathrm{~m}$; GII from 0.51 to $1 \mathrm{~m}$; GIII from 1.01 to $1.50 \mathrm{~m}$ and GIV above $\geq 1.51 \mathrm{~m}$; the plants height, the number of branches and the basal diameter were determined, in the period between March and December, 2007. The bromatological composition of leaves and branches of Capparis flexuosa was evaluated. It was showed, in all groups, that Capparis flexuosa presents a slow growth, even in the wet season. However, until August, we verified an increase in the number of branches, not dependent on the established group. During the showed period, we did not find differences $(p>0.05)$ between plants in terms of diameter, in all groups. The content of Crude protein (8.13\%); gross fiber (32.32\%); extract ether (5.37\%); Organic Matter (91.95\%); Ash (8.05\%); dry matter (47.1\%); Moisture (52.9\%) and Energy (5015 cal g-1) of Capparis flexuosa sugests that this species can be used as forage.
\end{abstract}

Key words - Forage plant. Capparaceae. Semiarid. Northeast Region. Nutritional values.

\footnotetext{
* Autor para correspondência

Recebido para publicação em 23/09/2009; aprovado em 26/03/2011

Parte da Dissertação de Mestrado do primeiro autor apresentado ao Programa de Pós-Graduação em Agronomia do Centro de Ciências Agrárias da UFPB

${ }^{2}$ Programa de Pós-Graduação em Agronomia do Centro de Ciências Agrárias/UFPB, Areia-PB, Brasil, netobiologia2@gmail.com

${ }_{3}^{3}$ Instituto Nacional do Semiárido, Campina Grande-PB, Brasil, albericio@uol.com.br

${ }^{4}$ Centro de Desenvolvimento Sustentável do Semiárido da UFCG, Sumé-PB, Brasil, alecvieria@yahoo.com.br

${ }^{5}$ Centro de Ciências Agrárias da UFPB, Areia-PB, Brasil, lpfelix@hotmail.com; divan@cca.ufpb.br
} 


\section{Introdução}

A Caatinga durante muito tempo vinha sendo descrita como pobre em biodiversidade, frágil e com pouca ou sem espécies endêmicas. Entretanto, estudos recentes mostram uma grande riqueza e endemismo de espécies, as quais têm um importante papel ecológico, econômico e social no Semiárido brasileiro. Dentro deste cenário, as forrageiras nativas têm contribuído para a sustentabilidade da pecuária nessa região. Nesse sentido, é percebido que a expansão da pecuária é marcante no Nordeste brasileiro e vários estudos definem muitas espécies da Caatinga com potencial forrageiro que são importantes fontes de alimento para os rebanhos, notadamente para a ovino-caprinocultura (GUIM et al., 2004; LINHARES et al., 2006; MOREIRA et al., 2006). Estudo da estacionalidade da produção, composição e disponibilidade da fitomassa predominante da Caatinga desempenha um significativo papel como estratégia para melhorar o manejo das forrageiras nativas. Entretanto, ainda são relativamente escassas as pesquisas com forrageiras a exemplo do feijão-bravo (Capparis flexuosa L.). Pertencente à família Capparaceae, esta é uma espécie de porte arbustivo-arbóreo com folhas perenes. Desenvolve-se em muitas áreas da região semiárida brasileira. Silva et al. (2009) em estudo realizado com essa forrageira verificou que as características número de brotações na época seca e comprimento do caule na época chuvosa foram capazes de explicar melhor o desenvolvimento do número de folhas, atuando de forma direta e inversamente proporcional sobre a variável básica, esse estudo permitiu concluir que o número de brotações exerce grande influência no número de folhas.

Considerando as suas peculiaridades, Pereira et al. (2007) afirma que a referida forrageira mantêm-se verde durante todo o ano, apresenta boa palatabilidade, isso é importantíssimo pois não há disponibilidade de outra forragem verde para a alimentação nas secas.

Portanto, considerando a relevância dessa espécie como alternativa forrageira para alimentação animal para o Nordeste do Brasil, o presente trabalho objetivou caracterizar aspectos relacionados com o crescimento e a bromatologia do feijão-bravo (Capparis flexuosa L.) em uma área no Curimataú, Semiárido paraibano.

\section{Material e métodos}

\section{Área de Estudo}

O estudo foi realizado no município paraibano de Barra de Santa Rosa. Situado na microrregião do Curimataú Ocidental, este município possui uma área de $825,01 \mathrm{~km}^{2}$ e está localizado entre as coordenadas $6^{\circ} 43^{\prime} 12^{\prime \prime} \mathrm{S}$ e $36^{\circ} 3{ }^{\prime} 39^{\prime}, \mathrm{W}$. O clima é quente e seco, típico do semiárido, com uma altitude de aproximadamente $457 \mathrm{~m}$.

Inserida na zona rural de Barra de Santa Rosa, a área de Caatinga amostrada na pesquisa ficou localizada no sítio Caiana (1.200 ha), o qual se encontra a uma distância aproximada de $12 \mathrm{~km}$ da sede municipal. Informações locais sobre o uso e ocupação dessa área, têm-se referenciado que a cerca de 25 anos foram retirados seletivamente árvores para utilização em carvoarias. Para o período analisado, a média anual de precipitação foi de $300 \mathrm{~mm}$. Relacionado à temperatura média anual do ar, esta variou de 26 a $29,6^{\circ} \mathrm{C}$. A média mensal da umidade relativa do ar na região variou entre $73 \%$ em fevereiro e $51 \%$ nos meses de outubro e novembro (INMET, 2007). Os dados de alguns atributos químicos de oito amostras de solo coletado na área de estudo na profundidade de 15 $\mathrm{cm}$ e analisado pelo Laboratório de Química e Fertilidade de Solo do Centro de Ciências Agrárias da Universidade Federal da Paraíba indicaram que a área de estudo apresenta características químicas de boa qualidade, isso a torna um local de solo fértil.

\section{Coleta e análise dos dados}

Para a análise de crescimento foi feita uma contagem do número de indivíduos de feijãobravo presente em 99 parcelas de 10 × 10 m cada. Sequencialmente foram estabelecidos, mediante a altura total da planta, quatro grupos: Grupo I: até $0,50 \mathrm{~m}$; Grupo II: de 0,51 a 1,00 m; Grupo III: de 1,01 a 1,50 m; Grupo IV: a partir de $1,51 \mathrm{~m}$.

Paracadaumdestes foramescolhidosaleatoriamente 10 plantas, com exceção do Grupo I por haver apenas 6 indivíduos na área de estudo. Portanto, observou-se um total de 36 indivíduos para acompanhamento do crescimento, sendo colocado nestes uma placa de alumínio numerada para sua identificação na parcela. Mediu-se mensalmente a altura total e o número de ramificações (até a secundária). Os dados foram analisados através de Teste de Médias calculando o desvio padrão.

No que concerne ao diâmetro da planta, este foi medido ao nível do solo (DNS) apenas em dois períodos, sendo primeiro no mês de março e o segundo em setembro de 2007. Os resultados obtidos também foram analisados pelo Teste de Médias calculando o desvio padrão.

Para a composição bromatológica do feijão-bravo foram coletados ramos no terço médio da copa sendo retirados folhas verdes e talos, no mês de dezembro de 2007. O material coletado foi conduzido ao Laboratório de Análises de Alimentos do Centro de Ciências Agrárias da Universidade Federal da Paraíba (CCA/UFPB), para a 
determinação de matéria seca(MS), matéria orgânica(MO), extrato etéreo $(\mathrm{EE})$, cinzas $(\mathrm{MM})$, proteína bruta $(\mathrm{PB})$, fibra bruta (FB), de acordo com a metodologia descrita por Silva (1990). Com a qual, procedeu-se com os seguintes princípios para as análises dos resultados obtidos:

- Para determinação da Matéria Seca e Umidade foi feito através dos processos de secagem definitiva e os resultados obtidos foram apresentados em porcentagem;

- Em relação ao Extrato Etéreo, partiu-se do seguinte principio: o éter utilizado no processo é aquecido até tornar-se volátil e, ao condensar, circula sobre a amostra em análise, arrastando toda a fração gordurosa e demais substâncias solúveis em éter. Este é recuperado em outro recipiente, enquanto que a gordura extraída é calculada por diferença de pesagem;

- Para o cálculo da Fibra Bruta, foi utilizada a amostra seca e desengordurada, a qual foi submetida à digestão ácida $\left(\mathrm{H}_{2} \mathrm{SO}_{4}-1,25 \%\right)$ e básica $(\mathrm{NaOH}-1,25 \%)$, durante 30 minutos em cada digestão. O resíduo orgânico é recebido em cadinho de vidro. Calculou-se a Fibra Bruta pela diferença de peso do cadinho antes e após a queima do resíduo em mufla, a $500{ }^{\circ} \mathrm{C}$;

- No que tange a determinação da Cinza, aqueceuse a amostra, até $500{ }^{\circ} \mathrm{C}$, durante 4 horas. $\mathrm{O}$ cálculo em porcentagem foi feito baseado no produto desse aquecimento e a diferença entre $100 \%$ e este resultado determinou o índice de Matéria Orgânica;

- Em relação à Proteína Bruta partiu-se do seguinte principio: as proteínas são decompostas na presença de ácido sulfúrico concentrado, a quente, com produção de sulfato de amônio. O sulfato de amônio resultante, na presença de solução concentrada de hidróxido de sódio, libera $\mathrm{NH}_{3}$ que é recebido na solução de ácido bórico. A amônia, na solução de ácido bórico, foi titulada com ácido sulfúrico e, assim, determinou-se o teor de nitrogênio. Para o teor de Proteína Bruta, multiplicou o resultado pelo fator 6,25 ;

- Foi utilizada uma bomba calorimétrica para determinação da Energia Bruta, a qual se refere à quantidade de calor liberado de determinada amostra, quando esta é completamente oxidada em ambiente rico em oxigênio.

\section{Resultados e discussão}

\section{Crescimento}

\section{a. Altura e Número de Ramos}

Na Figura 1 pode-se observar a evolução do crescimento do feijão-bravo (Capparis flexuosa), em termos de altura da planta. Verificou-se que os indivíduos dessa espécie cresceram dentro do período chuvoso na região (março a julho), entretanto, não houve diferença significativa, de acordo com o teste de médias, entre os meses de junho e julho. A partir daí, não ocorreu registro de crescimento. Há maior variabilidade de crescimento no Grupo I. Portanto, a espécie estudada apresenta mecanismos de defesa para se adaptar à seca. Isso faz com que o feijão-bravo tenha um ritmo de crescimento lento, característico da espécie, para se manter com folhas verdes durante todo o ano.
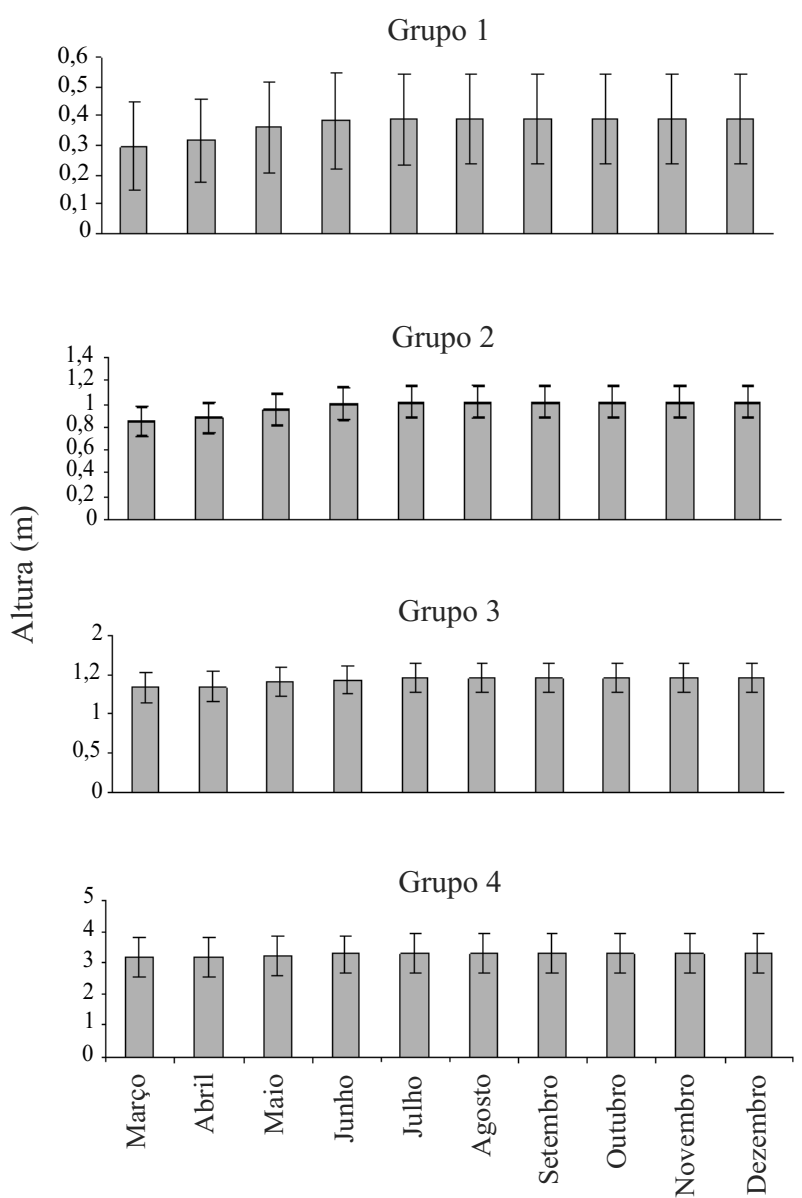

Meses

Figura 1 - Evolução do crescimento do feijão-bravo (Capparis flexuosa), em termos de altura da planta, em uma área de Caatinga em Barra de Santa Rosa - PB, durante o ano de 2007. As barras verticais representam o desvio padrão da média

Azevedo (2008) analisou o crescimento em altura das seguintes forrageiras: feijão bravo (Capparis cynophallophora), flor de seda (Calatropis procera), jurema preta (Mimosa tenuiflora), maniçoba (Manihot 
glaziovii) e marmeleiro (Croton sonderianus), de ocorrência natural na Caatinga, e constatou que não houve discrepância significativa entre plantas da mesma espécie, conferindo homogeneidade aos indivíduos amostrados. Comportamento semelhante também ocorreu nesse trabalho, em que se observou principalmente nos Grupos III e IV, diferença não significativa no crescimento em altura entre os indivíduos dos grupos.

Segundo Nascimento et al. (2006) o crescimento dos vegetais, como o de todos os organismos vivos, segue uma curva sigmóide, com uma fase inicial lenta, seguida por uma de rápido crescimento ou fase logarítmica, e, posteriormente, uma outra em que o crescimento é lento ou ausente. Finalmente, a curva toma a direção decrescente, coincidindo com a senescência das plantas.

Com relação à emissão de ramos, esta é feita de maneira lenta até o mês de agosto (FIG. 2), a partir daí, não houve registro de crescimento de ramos. Isso, provavelmente, é uma adaptação da espécie em relação ao longo período de estiagem observado no local. Assim, são esses mecanismos que fazem a planta ter folhas durante todo o ano, ou seja, a espécie além de se prevenir contra os efeitos do longo período de estiagem, possui, fisiologicamente, meios para manter suas folhas verdes durante todo o ano, ao contrário da maioria das espécies da Caatinga que perdem as folhas na estação seca (ALVES 2007; ALVES et al. 2009; OLIVEIRA et al, 2006; TROVÃO et al., 2007) a perda das folhas é essencial na estação desfavorável.

Lopes (2002) ao realizar estudos sobre o manejo do feijão-bravo em Taperoá (PB), verificou um aumento de crescimento médio em altura de 0,$45 ; 1,03$ e $0,44 \mathrm{~m}$; respectivamente para plantas intactas, podadas e induzidas (através do corte de botões florais dos galhos), no período de um ano de avaliação. O mesmo autor registrou a altura da forrageira de 1,89 e 1,81 $\mathrm{m}$ na primeira leitura chegando a 2,34 e 2,25 $\mathrm{m}$ ao final de um ano de leitura, respectivamente para plantas induzidas e intactas. Já Silva (2003), estudando o crescimento do feijão-bravo, verificou, entre maio de 2000 e maio de 2001, um aumento médio dos indivíduos de $0,46 \mathrm{~m}$.

De acordo com Pinto et al. (2006) as espécies forrageiras da Caatinga apresentam oscilações periódicas de crescimento e floração, havendo, entretanto, muita dúvida nos fatores que afetam essa periodicidade. Dos fatores ambientais que mais afetam o crescimento das espécies desse bioma, destaca-se o déficit hídrico, cuja resposta mais comum das plantas é a redução da produção da área foliar, fechamento dos estômatos, aceleração da senescência e abscissão das folhas.
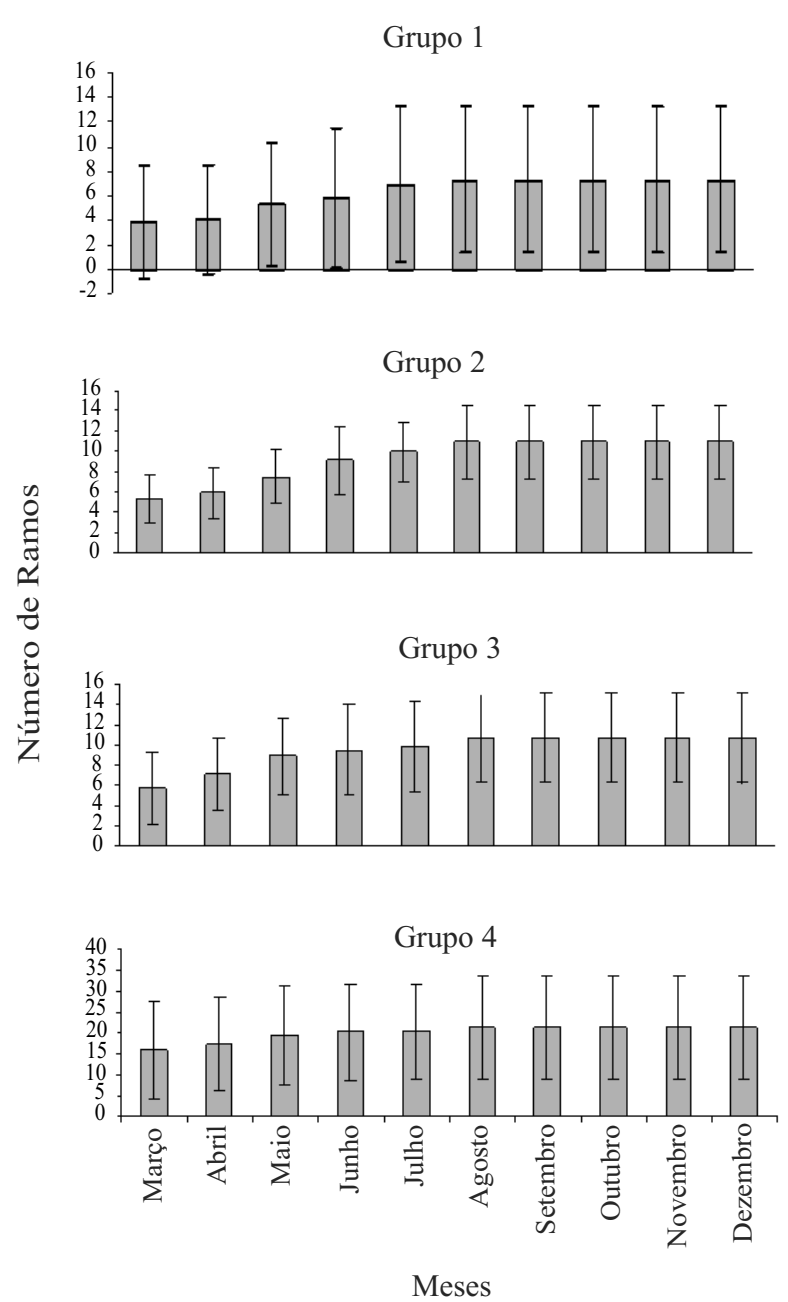

Figura 2 - Evolução do número de ramos do feijão-bravo (Capparis flexuosa) em uma área de Caatinga em Barra de Santa Rosa - PB, durante o ano de 2007. As barras verticais representam o desvio padrão da média

\section{b. Diâmetro}

Observou-se crescimento nos diâmetros variavelmente entre os indivíduos de cada grupo (FIG. 3). Entretanto, é significativo ressaltar a pouca visibilidade do registro em campo desse dado e a justificativa está centrada no curto período de observação (6 meses entre as duas coletas) que resultou no crescimento muito pequeno. Portanto, as diferenças de crescimento não são significativas de acordo com o teste de médias. Isso se deve ao fator adaptativo da espécie contra a estiagem que é característica das regiões do Semiárido. Há maior variação de crescimento no Grupo IV.

Resultados semelhantes aos encontrados nesse trabalho foi observado por Lopes (2002) com feijãobravo, em que se verificou a não ocorrência de diferenças 
significativas no diâmetro do caule das plantas para os efeitos de tratamentos e a interação tratamento*leitura.

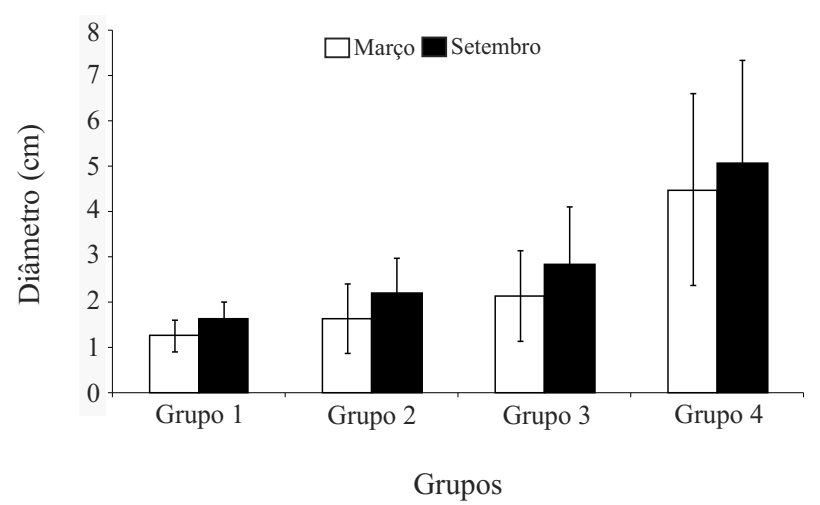

Figura 3 - Diâmetro de plantas, na altura basal, dos quatro grupos de feijão-bravo (Capparis flexuosa) em uma área de Caatinga em Barra de Santa Rosa - PB, durante o ano de 2007. As barras verticais representam o desvio padrão da média

Silva (2003) estudou o feijão-bravo e verificou um incremento médio no diâmetro de $3,03 \mathrm{~cm}$ entre maio de 2000 a maio de 2002. O mesmo autor ainda argumenta que o aumento nos diâmetros constituem uma característica que as plantas possuem para dar sustentação à copa, além de mecanismos de defesas contra o estresse hídrico, onde se aumenta o diâmetro do caule e reduz a produção de massa verde das árvores.

De modo geral, é observado por Taize Zeiger (2004) que entre todos os recursos de que a planta necessita para crescer, a água é o mais abundante e, ao mesmo tempo o mais limitante para a produtividade. A água é importante para a vida das plantas porque ela constitui a matriz e o meio onde ocorre a maioria dos processos bioquímicos essenciais à vida, assim, variações na disponibilidade de água no solo promovem diferenças no desenvolvimento do sistema radicular das plantas, afetando a absorção de nutrientes, devido às alterações no sistema radicular para exploração de maior volume de solo.

Nesse sentido, aspectos adaptativos das espécies da Caatinga estão relacionados à eficiência do uso da água pelas plantas; depreende-se que avaliações sobre o potencial hídrico das espécies podem fornecer importantes dados da natureza fisiológica dessas adaptabilidades (TROVÃO et al., 2004).

Pinto (2004) ao estudar variedades de maniçoba, observou que o crescimento vegetativo, em termos de altura e diâmetro do caule aumentou com a disponibilidade de água no solo. Percebe-se o comportamento semelhante desta forrageira com o feijão-bravo em função da disponibilidade de água, ou seja, quando ela esteve presente desencadeou processos de crescimento vegetativo, embora de forma muito lenta e variável entre os indivíduos da espécie. Pinto et al. (2008) estudando o sistema radicular do gergelim, amedoim e mamona em ciclos de deficiência hídrica, observou que houve alteração na morfologia das plantas, com redução do número de folhas e da área foliar.

Outros fatores que afetam o crescimento no plantio de culturas, em determinadas condições: o espaçamento entre linhas, observado por Severino et al. (2006) na mamoneira (Ricinus communis), a salinidade, afirmado por Silva et al. (2009) no pinhãomanso e a adubação (nitrogênio e potássio), verificado por Melo et al. (2006) na bananeira.

\section{Dados Bromatológicos}

Os componentes químicos encontrados no feijãobravo indicam que o mesmo está entre as espécies indicada como boa forrageira (TAB. 1).

Tabela 1 - Composição bromatológica do feijão-bravo (Capparis flexuosa) coletado em uma área de Caatinga em Barra de Santa Rosa-PB

\begin{tabular}{lc}
\hline \multicolumn{1}{c}{ Componentes químicos } & Médias \\
\hline Proteína bruta (PB) & $8,13 \%$ \\
Fibra bruta (FB) & $32,32 \%$ \\
Extrato etéreo (EE) & $5,37 \%$ \\
Matéria orgânica (MO) & $91,95 \%$ \\
Cinzas (MM) & $8,05 \%$ \\
Matéria seca (MS) & $47,1 \%$ \\
Umidade & $52,9 \%$ \\
Energia bruta & $5.015 \mathrm{cal} \mathrm{g}^{-1}$ \\
\hline
\end{tabular}

A jitirana (Merremia aegyptia L.) forrageira estudada por Linhares et al. (2006), na região de Mossoró - RN, obteve os seguintes resultados bromatológicos: 11,$5 ; 92,14 ; 14,86,2,02$, respectivamente para: MS, MO, PB, EE. Os resultados deste trabalho são maiores em: MS e EE.

Nascimento et al. (2001), estudou o mata-pasto (Senna obtusifolia (L.) Irwin e Barneby) em Campo Maior - PI, em diferentes idades e verificou: $\mathrm{PB}=25,55$; 21,07 e 20,$26 ; \mathrm{FB}=8,96 ; 14,65$ e 16,$31 ; \mathrm{EE}=2,11 ; 2,24$ 
e 2,28; respectivamente para as idades de 30; 60 e 90 dias. Comparando com este trabalho, o feijão-bravo obteve valores superiores em FB e EE em todas as idades.

Os resultados deste trabalho quando comparados com outras pesquisas com feijão-bravo a exemplo de Araújo et al. (2000), que registrou 92,80 de matéria seca, 89,46 de matéria orgânica, 13,47 de proteína bruta, 34,40 de fibra bruta, 8,31 de extrato etéreo e 10,54 de cinzas, observou-se que, com exceção da matéria orgânica, todos os componentes químicos estudados pelos autores foram superiores aos registrados neste estudo.

Em relação à Aroeira (Astronium urundeuva Engl.) outra espécie da Caatinga, estudado por Moreira et al. (2006), foi encontrado os seguintes percentuais: $\mathrm{MS}=55,31 ; \mathrm{PB}=11,44 ; \mathrm{MM}=5,56 ; \mathrm{EE}=2,55$. Os resultados encontrados pelo autor são maiores do que o presente trabalho com exceção do EE.

Vieira et al. (2005) coloca que a suplementação alimentar dos rebanhos nordestinos deve ser voltada para alternativas que diminuam os custos de produção, como o cultivo de plantas forrageiras de reconhecido valor nutritivo. $\mathrm{O}$ fornecimento de forrageiras existentes na região, na forma verde, fenada ou ensilada, pode suprir, em boa parte, a deficiência das pastagens nos períodos de estiagem a custos relativamente baixos.

Azevedo (2008) discute que em condições controladas, em espaçamento e densidades conhecidas, embora seja uma espécie de germinação tardia, a produção do feijão-bravo poderá ser expressiva na região semiárida, que convive com a escassez de alimento na maior parte do ano, sendo mais expressiva sua utilização também como banco de proteína e pastejo direto.

Quando comparada com outras forrageiras da Caatinga, o feijão-bravo apresenta-se como uma boa alternativa de forragem para os animais. Os quais necessitam de uma alimentação de boa qualidade principalmente no período de estiagem.

\section{Conclusão}

Nas condições edafoclimáticas em que foi realizado este trabalho, conclui-se que o feijão-bravo cresce lentamente dentro do período chuvoso. A emissão do número de ramos ocorreu até o mês de agosto. Observouse também que não houve discrepância significativa na medição dos diâmetros na espécie. Portanto, podese indicar o feijão-bravo como boa forrageira, devido às características químicas, para alimentação animal principalmente no período de estiagem.

\section{Agradecimentos}

Ao $\mathrm{CNPq}$ pelo auxílio financeiro tanto para realização desse estudo como para o curso de Mestrado em Agronomia oferecido pelo Centro de Ciências Agrárias da Universidade Federal da Paraíba.

\section{Referências}

ALVES, J. J. A., et al. Degradação da Caatinga: uma investigação ecogeográfica. Revista Caatinga, v. 22, n. 03, p. 126-135, 2009.

ALVES, J. J. A. Geoecologia da Caatinga no semi-árido do Nordeste Brasileiro. Climatologia e Estudos de Paisagem, v. 02, n. 01, p. 58-71, 2007.

ARAÚJO, E. C.; VIEIRA, M. E. Q.; CARDOSO, G. A. Valor nutritivo e consumo voluntário de forrageiras nativas da região semi-árida do Estado de Pernambuco: VI Feijão Bravo (Capparis flexuosa, L). In: Reunião Anual da Sociedade Brasileira de Zootecnia, 37., 2000, Viçosa. Anais... Viçosa: SBZ, 2000.

AZEVEDO, D. de O. Avaliação da produção de matéria verde e composição química, fracionamento e digestibilidade do feno de forrageiras de ocorrência natural na Caatinga. Dissertação (Mestrado em Zootecnia) 2008, 54f. Universidade Federal da Paraíba, Areia.

GUIM, A., et al. Padrão de Fermentação e Composição Químico-Bromatológica de Silagens de Jitirana Lisa (Ipomoea glabra Choisy) e Jitirana Peluda (Jacquemontia asarifolia L. B. Smith) Frescas e Emurchecidas. Revista Brasileira de Zootecnia, v. 33, n. 06, p. 2214-2223 (Supl. 3), 2004.

INMET - Instituto Nacional de Meteorologia. Relatório de Médias Mensais. 2007.

LINHARES, P. C. F., et al. Avaliação das qualidades forrageiras dajitirana (Merremia aegyptia) e seu potencial uso na alimentação animal. Revista Verde, v. 01, n. 01, p. 75-79, 2006.

LOPES, W. B. Estudo do feijão-bravo (Capparis flexuosa L.), como forrageira nativa no cariri paraibano. 2002, $80 \mathrm{f}$. Dissertação (Mestrado em Agronomia). Universidade Federal da Paraíba, Areia.

MELO, F. de B., et al. Crescimento e produção de frutos de bananeira cultivar "Grande Naine" relacionados à adubação química. Revista Ciência Agronômica, v. 37, n. 02, p. 246249, 2006.

MOREIRA, J. N., et al. da. Caracterização da vegetação de e da dieta de novilhos no Sertão de Caatinga Pernambuco. Pesquisa Agropecuária Brasileira, v. 41, n. 11, p. 1643-1651, 2006.

NASCIMENTO, H. T. S.; NASCIMENTO, M. P. S. C. B.; RIBEIRO, V.Q. Valor Nutritivo do Mata-Pasto (Senna obtusifolia (L.) Irwin \& Barneby) em Diferentes Idades. Embrapa - Boletim de Pesquisa e Desenvolvimento, 33, 2001, 18p. 
NASCIMENTO, M. P. S. C. B., et al. Análise do crescimento e do valor forrageiro de mata-pasto para a produção de feno. Revista Caatinga, v. 19, n. 03, p. 215-220, 2006.

OLIVEIRA, M. B. L., et al. Trocas de energia e fluxo de carbono entre a vegetação de Caatinga e atmosfera no Nordeste Brasileiro. Revista Brasileira de Meteorologia, v. 21, n. 3b, p. 378-386, 2006.

PEREIRA, N. T., et al. Análise Nutricional da espécie forrageira feijão-bravo (Capparis flexuosa). In: CONGRESSO NORTENORDESTE DE QUÍMICA, 1., 2007, Natal. Resumos... Natal: Associação Norte-Nordeste de Química, 2007.

PINTO, C. de M., et al. Crescimento, distribuição radicular em amedoim, gergelim e mamona a ciclos de deficiência hídrica. Revista Ciência Agronômica, v. 39, n. 03, p. 429-436, 2008.

PINTO, M. do S. de C. Crescimento Vegetativo e Composição Química das Cultivares de Maniçoba (Manihot pseudoglaziovii e Manihot piauiensis) em Função da Disponibilidade de Água no Solo. 2004, 104f. Dissertação (Mestrado em Zootecnia), Centro de Ciências Agrárias, Universidade Federal da Paraíba, Areia.

PINTO, M. S. C.; CAVALCANTE, M. A. B.; ANDRADE, M. V. M. Potencial forrageiro da caatinga, fenologia, métodos de avaliação da área foliar e o efeito do déficit hídrico sobre o crescimento de plantas. Revista Electrónica Veterinária, v. 07, n. $04,2006$.

SEVERINO, L. S., et al. Crescimento e produtividade da mamoneira influenciada por plantio em diferentes espaçamentos entre linhas. Revista Ciência Agronômica, v. 37, n. 01, p. 50-54, 2006.
SILVA, D. J. Análise de alimentos (métodos químicos e biológicos). 2.ed. Viçosa: UFV, Impressão Universitária, 1990. 165 p.

SILVA, E. N. da, et al. Acumulo de íons e crescimento de pinhão-manso sob diferentes níveis de salinidade. Revista Ciência Agronômica, v. 40, n. 02, p. 240-246, 2009.

SILVA, J. C. A. da. Estudo fenológico do feijão-bravo (Capparis flexuosa L.) no cariri Paraibano. 2003, 28f. Trabalho de Conclusão de Curso (Graduação em Agronomia)Universidade Federal da Paraíba. Areia.

SILVA, M. A., et al. Análise de trilha para caracteres morfológicos do feijão-bravo (Capparis flexuosa) no cariri paraibano. Archivos de Zotecnia, v. 58, n. 221, p. 121-124, 2009.

TAIZ, L.; ZEIGER, S. Plant physiology. Redwood City: The Benjamim Cummings, 2004. 690p.

TROVÃO, D. M. B. M., et al. Avaliação do potencial hídrico de espécies da Caatinga sob diferentes níveis de umidade do solo. Revista de Biologia e Ciências da Terra, v. 04, n. 02, 2004.

TROVÃO, D. M. B. M., et al. Variações sazonais de aspectos fisiológicos de espécies da Caatinga. Revista Brasileira de Engenharia Agrícola e Ambiental, v. 11, n. 03, p. 307-311, 2007.

VIEIRA, E. L., et al. Composição Química de Forrageiras e Seletividade de Bovinos em Bosque-de-Sabiá (Mimosa caesalpiniifolia Benth.) nos Períodos Chuvoso e Seco. Revista Brasileira de Zootecnia, v. 34, n. 05, p. 1505-1511, 2005. 